\title{
Current smokers' perception of cigarette graphic health warnings and smoking habits: a cross sectional study from Nepal
}

\author{
Shiva Raj Mishra ${ }^{1,2^{*}}$, Parash Mani Bhandari ${ }^{3}$, Sujan Babu Marahatta ${ }^{4}$, Hari Krishan Singh Rana ${ }^{5}$, Pawan Acharya ${ }^{6}$, \\ Vishnu Khanal ${ }^{7,1}$ \\ ${ }^{1}$ Nepal Development Society, Chitwan, Nepal ${ }^{2}$ University of Western Australia, School of Population Health, WA, Australia ${ }^{3}$ Maharajgunj Medical Campus, Institute \\ of Medicine, Tribhuvan University, Kathmandu, Nepal ${ }^{4}$ Manmohan Memorial Institute of Health Sciences, Lalitpur, Nepal ${ }^{5}$ Sanjeevani College of Medical Sciences, \\ Rupandehi, Nepal ${ }^{6}$ University of Southern Denmark, Denmark ${ }^{7}$ School of Public Health, Curtin University, Australia
}

\begin{abstract}
Background: Nepal introduced Tobacco Products (Control and Regulatory) Act in 2011. This act has mandatory provision of enlarged graphical health warning in Nepali language on at least $75 \%$ area on the package of all the tobacco products. This study examined the perception of cigarette graphic health warnings and smoking habits among current smokers.
\end{abstract}

Received:

19 November 2015

Revised:

04 January 2016

Accepted:

15 January 2016

\section{${ }^{*}$ Correspondence:}

shivarajmishra@gmail.com Nepal Development Society, Chitwan, Nepal.
Methodology: This is a cross-sectional study conducted in Butwal sub-metropolitan city in Rupandehi district of Nepal. Among 19 wards of the sub-metropolitan city, four wards were selected randomly by computer-generated codes. Enumerators purposively selected 10 shops from each ward, then recruited every third cigarette buyer from each shop to make a total of five. Smoking status was ascertained by asking if they had ever smoked in last thirty days. We approached 200 people, of whom 40 (20.0\%) didn't agree to participate and $10(5.0 \%)$ didn't smoke currently. Thus, information from 150 current smokers was finally included in the analysis.

Results: Nearly $71 \%$ of respondents said they would smoke even if the price of cigarette was doubled. Similarly, $55.3 \%$ reported that they had intention to quit smoking, followed by $62.0 \%$ agreeing on taxation of cigarette and tobacco products is essential. Nearly $81 \%$ said it is necessary to keep health warnings in the package of cigarette. About $87 \%$ knew that the Government of Nepal has introduced some regulations to control tobacco products. Nearly $80 \%$ of respondents had heard of new provision on enlarged graphic health warning on cigarette packages. More than one-fourth $(26.7 \%)$ had reduced the frequency of smoking since they started using packages with enlarged graphic health warning.

Conclusion: Majority had heard of graphic health warning on cigarette packages. Greater than a half of the respondents had intention to quit smoking, and nearly two-third identified taxation as important means to control smoking. A quarter of respondents reported that they forewent smoking after they started using new packages with enlarged graphic health warning. Further research on impact of graphic health warning on smoking levels through repeated cross sectional studies can be the future research priority.

Keywords: tobacco; cigarette; packaging and labeling; cessation; Nepal.

Suggested citation: Mishra SR, Bhandari PM, Marahatta SB, Rana HKS, Acharya P, Khanal V. Current smokers' perception of cigarette graphic health warnings and smoking habits: a cross sectional study from Nepal. Health Prospect. 2016;15(1):02-08.

\section{Introduction}

Worldwide, tobacco kills 5.4 million people in a year (1). According to the World Health Organization (WHO), one in ten adult deaths in the world is attributable to tobacco consumption. Health hazards of tobacco consumption range from elevated risk of cardiovascular and respiratory diseases to oral, lung and many other cancers. In Nepal, 15,000 deaths annually can be attributed to the use of tobacco products (2). Prevalence of smoking in males in Nepal is $29.8 \%$ while that among females is $8.7 \%(3,4)$.

World Health Organization - Framework Convention on Tobacco Control (WHO-FCTC) has set up measures necessary for restricting tobacco marketing. There are many standards set by WHO-FCTC including, but not limited to, labeling requirements, tax and price policies, and tobacco advertising 
(5). Till date, 180 parties have ratified this convention (6). Many countries have put a restriction on tobacco advertisement and promotion. In these countries, as cigarette package is the sole way of advertising, packages are developed in such a way that it is eye-catching and appealing. In some occasions, the package is targeted to special segment of population using various commercial techniques. For instance, package targeting women use attributes of slimness and glamour (7) whereas, the packs targeting the youths use attractive and fashionable images, and innovative constructions and methods of openings in pack structures (8).

For restricting the opportunity of tobacco producers to influence the consumers through various design elements in packages, plain packaging and enlarged graphic health warning (GHW) of tobacco products have been proposed by WHOFCTC $(5,6)$. Following the provision of WHO-FCTC, Australia introduced legislation for GHW and plain tobacco packaging that has resulted in a significant reduction in personal pack display and smoking rates on outdoor areas of cafes, restaurants and bars (9). Also, the number of smokers agreeing that their pack is attractive, appealing and fashionable significantly has decreased over time (10). Another evidence from Australia has also shown that persons smoking from plain packs are more likely to have thought about quitting at least once a day in the past week, and to rate quitting as a higher priority in their lives (11). Studies have also shown that plain packaging with fewer brandings and larger health warnings reduces the ratings of appeal (12), smoothness and taste $(13,14)$. Experimental research studies with simulated plain packages have reported a reduction in the false beliefs about health hazards $(15,16)$ and increased intention to and rates of quitting smoking. Additionally, studies have found that packages containing large warning labels are more effective in reducing demand of cigarettes than traditional text only packages $(17,18)$.

\section{New enlarged graphic health warnings in Nepal}

In response to the high smoking rates and preventable deaths attributed to cancer among smokers, Nepal banned the advertisement of tobacco products in electronic and print media in 1992 (19), and ratified FCTC in 2006; as a result a new Tobacco Products (Control and Regulatory) Act was endorsed in 2011. This act, though does not include all the provisions needed in a plain package, has made mandatory provision of enlarged GHW in Nepali language on at least 75\% area of the package of all the tobacco products. The act has provisions including, but not limited to, smoke free public places, workplaces and public transportation, a ban on advertisement, a ban on selling or distributing free tobacco to a child aged $<18$ years and a pregnant mother, a ban on the use of tobacco as a gift item, a ban on use of misleading attributes in packages, and ban on logo, picture or words that can attract children (20). (Figure 1) Recently in 2014, the act has been amended making it mandatory for the tobacco companies to devote $90 \%$ of the package with pictorial health warnings. With this amendment, which has not been fully implemented though supposed to put in to action from May 2015, Nepal has one of the highest requirements of graphical warnings in the world (21).

One former study conducted in Kathmandu valley reported positive public response to the provisions of Tobacco Products (Control and Regulatory) Act, whereas, participants perceived that administrative and legal structures for implementation of this act were poor (22). However, there is dearth of information about the perception of GHW and smoking habit among current smokers after the Tobacco Products (Control and Regulatory) Act came into effect. This study examined the perception of cigarette GHW and smoking habit, among current smokers from Nepal.

\section{Methods}

\section{Study setting}

Rupandehi district is located in southern plains in Terai region of Western Development Region, Nepal. The district has a total population of 880,196 as of 2011(23). According to the Nepal Demographic and Health Survey, Western Development Region has $35.1 \%$ (men $29.2 \%$; women $5.9 \%$ ) prevalence of tobacco smoking.

\section{Sample, tool and data collection}

A cross sectional study was conducted between July and August 2014 in Butwal sub metropolitan city in Rupandehi district of Nepal. We used computer-generated codes to select the four out of nineteen wards randomly. In Nepal, wards are the smallest administrative units within a city/village. Enumerators first located the ward administrative office in each ward, and then selected 10 shops consequently to the same side of the road in which the ward office was located. Approaching every third cigarette buyers with a total of five from each shop, we reached 50 cigarette buyers from each ward. Every third cigarette buyer was asked if he or she has ever smoked. Out of the 200 people approached for study, 40 (20.0\%) didn't agree to participate and $10(5.0 \%)$ didn't currently smoke. Thus, information from 150 current cigarette smokers was finally included in the analysis.

Four trained field enumerators conducted face-to-face interviews. Study tool was adapted from earlier literatures $(24,25)$. The questionnaire was pretested among ten current smokers from the same setting to test cultural adaptability and those who participated were not included in final analysis.

Information on socio-demographic characteristics, knowledge regarding recently introduced legal provisions, smoking behaviors and preferences were recorded based on face-to-face interview conducted with respondents.

\section{Definition of variables}

A current smoker is defined as a person who smoked at least once in the last 30 days. Ethnicity was classified as Dalit, Janajati/Adibashi, Madheshi, Muslim, Brahmin/Chhetri based on Health Management Information System Classification of Nepal $(26,27)$. Respondents were asked for the family members with whom they have smoked together. Respondents were asked, "Have you heard of any regulation introduced to regulate tobacco products?" Then, they were presented with the question "Have you previously heard of GHW?"

Participants' feelings about pack with GHW were assessed for: feeling embarrassed, vulnerable and courageous with question structured as 'How embarrassed do you feel while smoking cigarette from this package?' Pack perceptions were assessed for: cheap, attractive, appealing and quality-rich with questions like 'How fashionable does this package appear to you?' Health warnings related to: noticeable, serious, believable and informative were assessed by questions like 'How noticeable 
is the health warning in this package?' Smoking experience related to: enjoyable and satisfying were assessed by questions structured as 'How enjoyable is smoking cigarette from this package?' Response to all these statements were recorded in the likert scale of 'very much', 'neutral' and 'not much'.

Additionally, respondents were presented with a list of potential behavioral changes after initiating to smoke from the packages with GHW, and asked to respond if any of the behavior was true for them. Potential behavior changes were: think of quitting, smoke less around others, cover the pack, keep pack out of sight, smoke less frequently, feel vulnerable and stub out a

\begin{tabular}{|c|c|}
\hline \multicolumn{2}{|c|}{ Table 1: Demographic characteristics of respondents $(n=150)$} \\
\hline Characteristics & n (\%) \\
\hline \multicolumn{2}{|l|}{ Sex } \\
\hline Male & $113(75.3)$ \\
\hline Female & $37(24.7)$ \\
\hline Age (years) & $36.5 \pm 15.2$ \\
\hline$<18$ & $7(4.7)$ \\
\hline $18-24$ & $39(26.0)$ \\
\hline$>24$ & $104(69.3)$ \\
\hline \multicolumn{2}{|l|}{ Ethnicity } \\
\hline Dalit & $16(10.7)$ \\
\hline Janajati/Adibashi & $64(42.7)$ \\
\hline Madheshi & $11(7.3)$ \\
\hline Muslim & $5(3.3)$ \\
\hline Brahmin/Chhetri & $49(32.7)$ \\
\hline Others & $3(2.0)$ \\
\hline \multicolumn{2}{|l|}{ Educational status } \\
\hline Illiterate & $24(16.0)$ \\
\hline Literate & $17(11.3)$ \\
\hline Primary level & $15(10.0)$ \\
\hline Lower secondary level & $15(10.0)$ \\
\hline Secondary level & $24(16.0)$ \\
\hline Intermediate level & $19(12.7)$ \\
\hline Bachelor or above & $36(24.0)$ \\
\hline \multicolumn{2}{|l|}{ Occupation } \\
\hline Agriculture & $23(15.3)$ \\
\hline Business & $21(14.0)$ \\
\hline Service & $33(22.0)$ \\
\hline Labor & $10(6.7)$ \\
\hline Foreign employment & $13(8.7)$ \\
\hline Unemployed & $50(33.4)$ \\
\hline Monthly family income (USD) & $448.9 \pm 439.5$ \\
\hline$<100$ & $17(11.3)$ \\
\hline $100-500$ & $97(64.7)$ \\
\hline$>500$ & $36(24.0)$ \\
\hline Age of smoking initiation (years) & $18.2 \pm 5.1$ \\
\hline$<18$ & $86(57.3)$ \\
\hline $18-24$ & $47(31.3)$ \\
\hline$>24$ & $17(11.3)$ \\
\hline Monthly expenditure in cigarette (USD) & $8.4 \pm 8.2$ \\
\hline$<2.5$ & $19(12.7)$ \\
\hline $2.5-5.0$ & $61(40.7)$ \\
\hline$>5.0$ & $70(46.7)$ \\
\hline \multicolumn{2}{|l|}{ Family companion in smoking } \\
\hline Parents & $9(6.0)$ \\
\hline Brothers/sister & $18(12.0)$ \\
\hline Children & $12(8.0)$ \\
\hline Other relatives & $19(12.7)$ \\
\hline Alone & $71(47.3)$ \\
\hline Others & $21(14.0)$ \\
\hline
\end{tabular}

cigarette. Response to these items was recorded as either 'yes' or 'no. Other questions responded were presented which included: socio-demographic details, change in smoking habit if taxation increased or price doubled, perceived need of health warnings and intention to quit.

\section{Data analysis}

Data was entered in EpiData 3.1 and analyzed using SPSS 20 (IBM SPSS Statistics). The socio-demographic characteristics of the study participants were reported as frequency and percentages. The knowledge, attitude and practices related to GHW were also reported in percentages.

\section{Research ethics}

This research obtained ethical approval from Institutional Review Board of Manmohan Memorial Institute of Health Sciences. The study objectives were clearly explained to the participants before the data collection. Written informed consent was obtained from each participant. Respondents' right not to answer any question or leave the interview at any time during the data collection was respected. No monetary incentives was provided.

\section{Results}

\section{Demographic characteristics of respondents}

Three-fourth of the respondents were male (75.3\%). High proportions of respondents were aged $>24$ years $(69.3 \%)$, belonged to Janajati/Adibashi ethnic group (42.7\%), had bachelor level of education or above (24.0\%) and were unemployed (33.4\%). When asked about the age at which they started smoking, more than half (57.3\%) said that they had started smoking at age of less than 18 years. Highest proportion (46.7 \%) of respondents spent $>5.0$ USD in cigarettes per month. Majority of the participants smoked alone (47.3\%), followed by smoking with siblings (12.0\%) and other family members (14.0\%). (Table 1)

\section{Knowledge about graphic health warning}

Nearly $80 \%$ of respondents had heard of new provision on enlarged GHW on cigarette packages. About $87 \%$ knew that the Government of Nepal has introduced some regulations to control tobacco products. Prohibition on smoking in public places was known to $37.3 \%$, followed by prohibition in selling cigarette to children less than 18 years of age (25.3\%), prohibition to sell individual pieces of cigarettes by retailers (10.7\%), prohibition to smoke within the 500-meter premise of hospitals or public institutions (10.0\%) and prohibition to advertise tobacco products in digital media or graphic media (3.3\%). (Table 2)

\section{Attitude and perception towards graphic health warning} Nearly $71 \%$ of the respondents said they would smoke even if the price of cigarette was doubled. Similarly, 55.3\% reported that they had intention to quit smoking followed by $62.0 \%$ agreeing that taxation of cigarette and tobacco products is essential. Nearly $81 \%$ said it is necessary to keep health warnings in the package of cigarette. (Figure 2)

When asked about various statements to measure perception towards GHW, 72.0\% agreed that the health warnings in the package is informative, followed by message in the pack is noticeable $(73.3 \%)$, message is serious $(68.0 \%)$, and message is believable (56.0\%). Similarly, respondents felt vulnerable (45.3\%) 
Table 2: Knowledge and perception about graphic health warning $(n=150)$

\begin{tabular}{lr}
\hline Characteristics & $\mathbf{n}(\%)$ \\
\hline Heard of graphic health warning? & $119(79.3)$ \\
Yes & $31(20.7)$ \\
No & $130(86.7)$ \\
Heard of any regulation to control tobacco products? & $20(13.3)$ \\
Yes & \\
No & $38(25.3)$ \\
Heard of the following regulations? & \\
Selling cigarette to children less than 18 years of age if prohibited & $16(10.7)$ \\
It is not allowed for retailers to sell individual pieces of cigarettes & $56(37.3)$ \\
Smoking in public place is prohibited & $15(10.0)$ \\
It is not allowed to smoke $1 / 2$ kilometer premises of hospital or & $5(3.3)$ \\
It is not allowed to advertise tobacco in digital or graphic media & \\
Effect keeping information in package of cigarette can have ${ }^{\#}$ & \\
It encourages to stop smoking & $49(32.7)$ \\
It informs about the health hazards of smoking & $45(30.0)$ \\
It decreases the number of sticks of cigarette smoke per day & $14(9.3)$ \\
It informs to stop smoking in public place & $17(11.3)$ \\
It has no effect & $23(15.3)$ \\
&
\end{tabular}
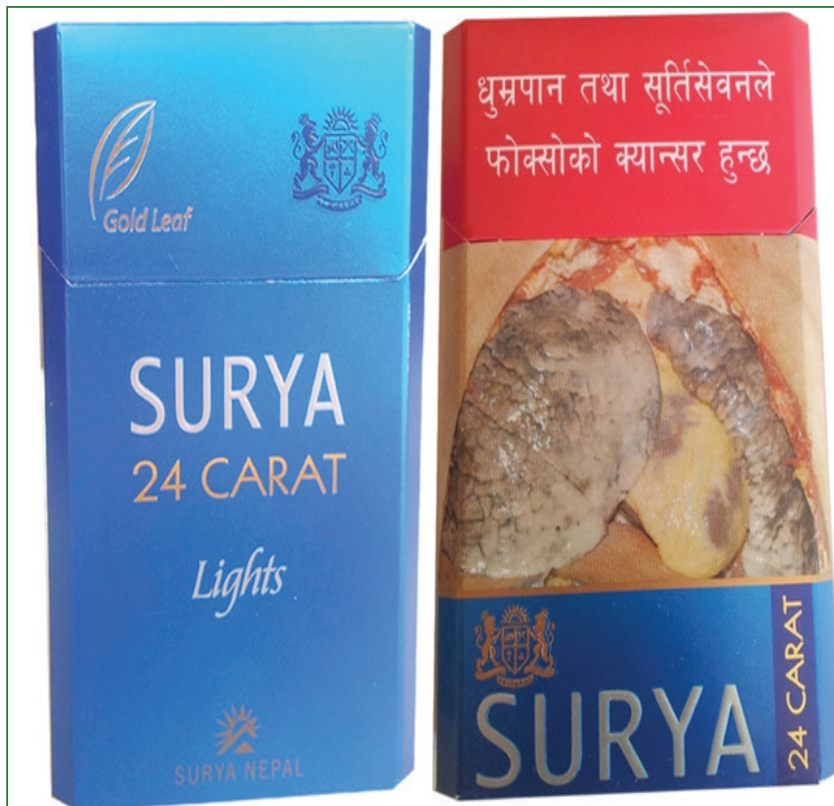

Figure 1: Branded and new package with enlarged GHW in Surya cigarette

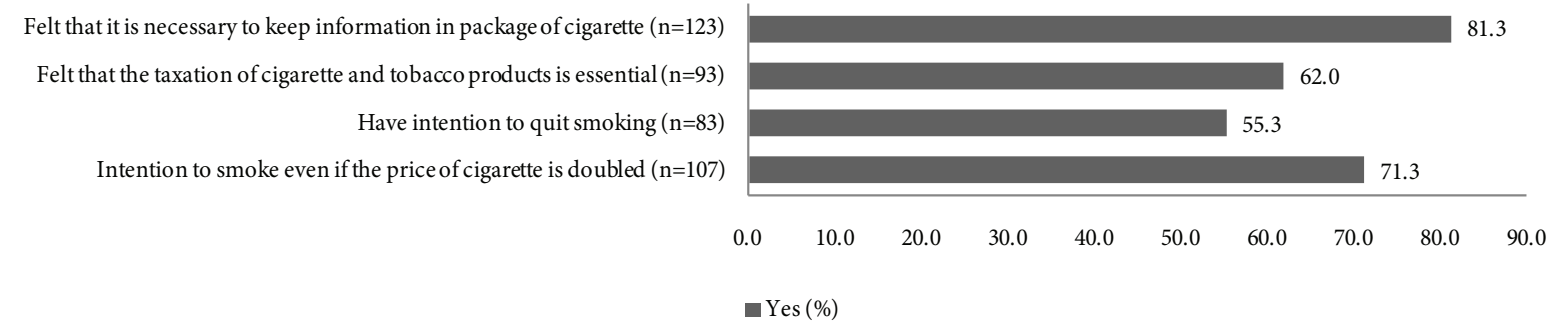

Figure 2: Intention to quit smoking and attitude towards doubling price, taxation and information in package of cigarette

and embarrassed (42.7\%) while smoking from package with GHW. In addition, respondents found the new packs satisfying $(44.7 \%)$, enjoyable $(40.7 \%)$, affordable $(35.3 \%)$, quality-rich $(29.3 \%)$ and attractive $(28.0 \%)$. A small proportion of respondents said that they felt more courageous while smoking from pack with GHW (18.0\%) and found the new pack more appealing (11.3\%).

(Figure 3)

\section{Practices related to enlarged graphic health warning}

When asked about what their behavior was since they started to smoke from packages with GHW, participants indicated the following actions: forego smoking cigarette (26.7\%), stub out cigarette (16.7\%), smoke less around others (12.0\%), think about quitting smoking (10.0\%), feel more vulnerable after seeing the GHW in the package (8.7\%), cover the pack (6.0\%) and keep pack out of sight (3.3\%). (Figure 4 )

\section{Discussion}

Our study found that almost half of the respondents had intention to quit following the introduction of enlarged GHW in tobacco products in Nepal, which signals a positive effect of GHWs. We also found that respondents had a favorable attitude towards the GHW, for instance, majority of respondents saying the anti-tobacco message in the new package is noticeable and less appealing.

Favorable attitude towards GHW in this study accords the earlier study among adult smokers which found that new packages with enlarged GHW increased promoted knowledge on consequences of smoking (28) and Flemish adolescents' study, which revealed that plain packages are perceived as less attractive, cheap and unreliable by young people (24). Another Australian study showed plain packaging with larger GHWs reduced misinformation about harms of smoking, appeal and increased health warning effectiveness among young and adults (29). According to the theory of reasoned action, person's voluntary behavior depends on his attitude toward that behavior (30). Thus, current smokers-who have more favorable attitude towards GHW-may stop smoking in future. The current package also has unattractive image, due to which the health warning becomes stronger and eye-catching (24). Rob Cunningham et al. (31) stated unattractive images not only reduce positive imagery but also create negative imagery discouraging smoking. It also increases perceived susceptibility and severity to diseases (32).

Nearly $71 \%$ of respondents said they would smoke even if the price of cigarette is doubled which shows that increase in taxation alone is not adequate in Nepal where the price of tobacco is less expensive and tobacco products are available everywhere. Nearly $81 \%$ said it is necessary to keep health warning information in the package of cigarette, which shows that the public acceptance of the approach is high.

More than a half of participants reported that they had intention to quit smoking, which illustrates that more reduction in smoking rates is achievable if respondents who are willing 
The health related message in the package is noticeable $(n=110)$

The health related information in the package is informative $(n=108)$

The health related message in the package is serious $(n=102)$

The health related information in the package is believable $(\mathrm{n}=84)$

Feel vulnerable while smoking from the package $(n=68)$

Feel satisfied while smoking from the package $(n=67)$

Feel embarrased while smoking from the package $(n=64)$

Feel enjoyable while smoking from the package $(n=61)$

The package seems cheap $(n=53)$

The package seems quality-rich $(\mathrm{n}=44)$

The package seems attractive $(n=42)$

Feel courageous while smoking from the package $(n=27)$

The package seems appealing $(n=17)$

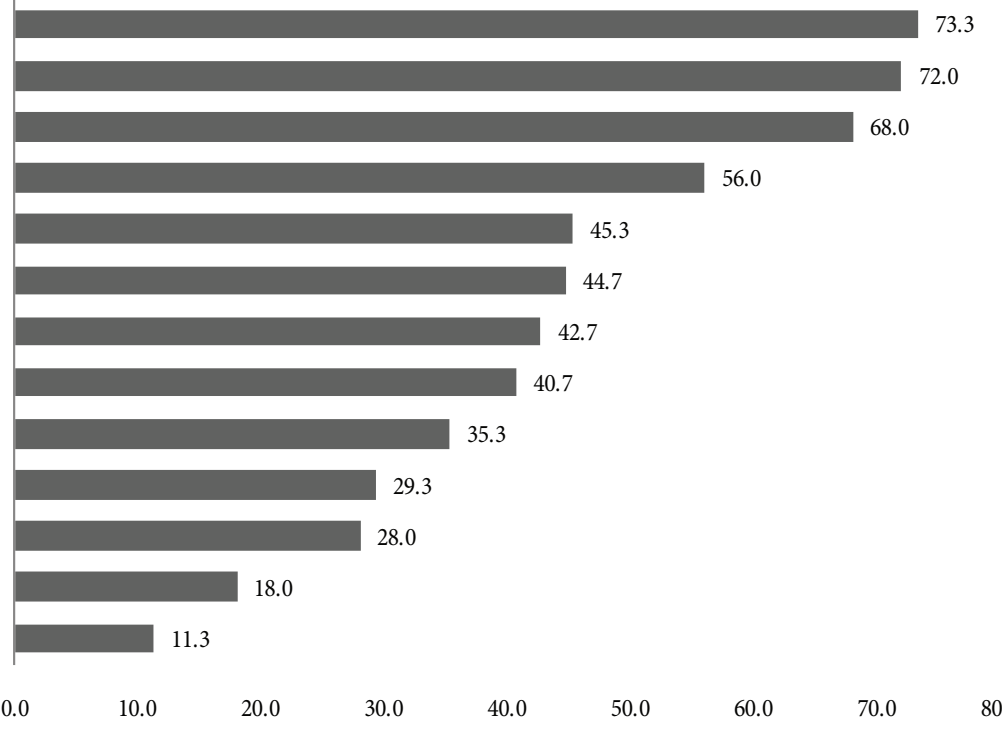

- Yes (\%)

Figure 3: Perception towards enlarged GHW

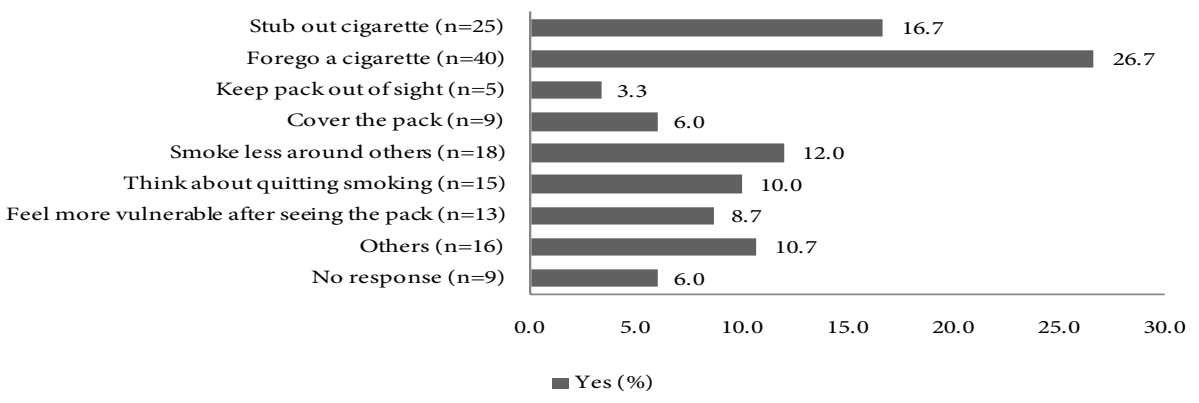

Figure 4: Participants' practices after starting to smoke form package with enlarged GHW

to quit are provided with more support for smoking cessation. The mode of support could be peer support counseling (33) for craving management, pharmacologic interventions, or nicotine replacement therapy (34). Similarly, a review has stated that group behavioral therapy, intensive physician advice, individual counseling, telephone counseling, nursing interventions, and tailored self-help interventions can greatly help smoking cessation $(35,36)$.

This study is the first to document public perception and attitude towards cigarette GHW in Nepal. While there is always a tough competition between the corporate tobacco industries trying not to obey the new packaging rules and the government posing them (rules), the policy makers should be more informed about the strong positive benefits of GHW so that the monitoring could be effectively done. In addition, tobacco companies often cheat on compliance with rules, for example, they place Value Added Tax (VAT) stickers above health warning (Figure 5). This should be carefully monitored. Therefore, the findings of this study are useful for public health authority in Nepal.

However, many limitations should be considered while interpreting the findings. Firstly, being carried out in a small sample with respondents purposively drawn due to resource constraints, the generalizability of our findings may be reduced. Smokers who buy the cigarette from the shop might not be the true representative of those who currently smoke. Some smokers may not buy cigarette themselves but ask others to buy cigarette for them, so they were less likely to be recruited in data collection.

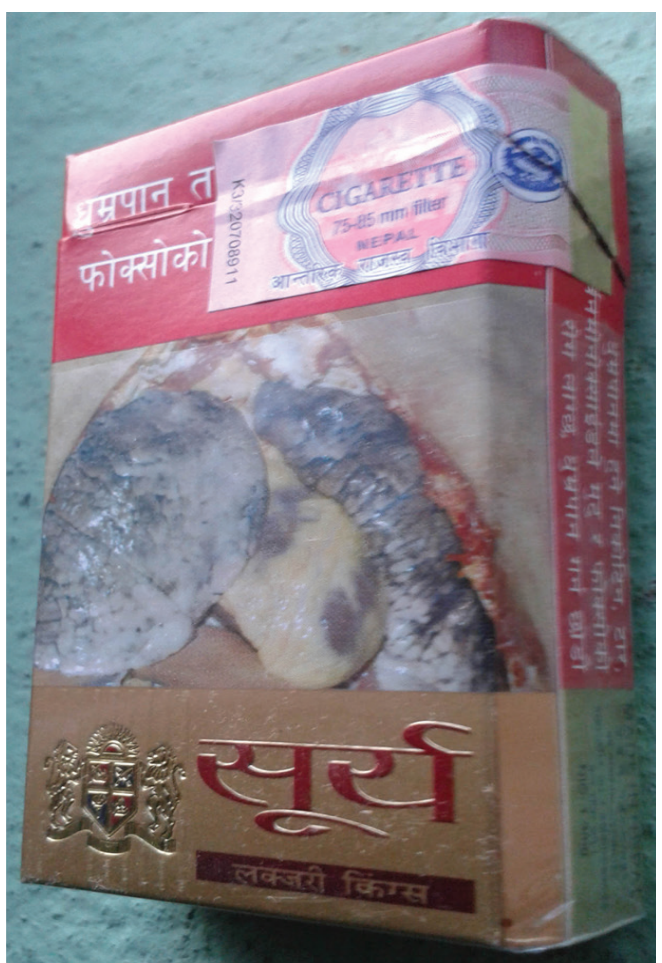

Figure 5: Newly introduced package with a VAT sticker covering the health warning 
In a more ideal way, repeated cross-sectional study or longitudinal study is necessary to explore the impact of GHW on smoking habit. Nevertheless, the findings of this study state that people have a positive attitude towards provision of GHW in Nepal.

\section{Conclusion}

We found a favorable attitude from the majority of smokers regarding the introduction of GHW. The majority had heard of GHW on cigarette packages. We found that a quarter of respondents forewent smoking, and greater than half of the respondents had intention to quit smoking. Furthermore, two-third of the respondents perceived taxation important for controlling smoking. Further research on impact of GHW on smoking levels through repeated cross sectional studies can be future research priority.

\section{Abbreviations}

FCTC: Framework Convention on Tobacco Control; GHW: Graphic Health Warning; UK: United Kingdom; USD: United States Dollar; WHO: World Health Organization.

\section{Competing interests}

The authors declare that they have no competing interests.

\section{Authors' contributions}

SRM conceived the study design. PMB and HKSR carried out the field level data collection. SRM and PMB carried out the data analysis. SRM and PMB wrote the first draft of the manuscript. SBM, PA and VK contributed in the literature review and interpretation of results. All the authors contributed in revision of manuscript and approved on the final version of manuscript.

\section{Acknowledgements}

We would like to acknowledge the support from Manmohan Memorial Institute of Health Sciences and Nepal Development Society to carry out this study. We are equally indebted to all the participants who participated in this study.

\section{Author E-mails}

1'shivarajmishra@gmail.com, ${ }^{3}$ parashmanibhandari@gmail.com,

${ }^{4}$ sujanmarahatta@gmail.com, ${ }^{5}$ ranahari7172@gmail.com,

6ac.pawan@gmail.com, ${ }^{7}$ khanal.vishnu@gmail.com

\section{References}

1. World Health Organization. WHO report on the global tobacco epidemic, 2008: the MPOWER package. 2008.

2. Ministry of Health and Population. Tobacco Control Reference Book. Kathmandu, Nepal, 2011.

3. Khanal V, Adhikari M, Karki S. Social determinants of tobacco consumption among Nepalese men: findings from Nepal Demographic and Health Survey 2011. Harm Reduct J. 2013; 10(1):40.

4. Khadka BB, Karki YB. Further analysis of 2011 Nepal Demographic and Health Survey on Tobacco Data. Kathmandu: National Health Education, Information and Communication Centre/MoHP, The Population, Health and Development (PHD) Group, 2013.

5. World Health Organization. WHO Framework Convention on Tobacco Control. Geneva, Switzerland, 2003.

6. WHO Framework Convention on Tobacco Control. Parties to the WHO Framework Convention on Tobacco Control. http://www.who.int/fctc/ signatories_parties/en/. Accessed January 22, 2016.

7. Hammond D, Doxey J, Daniel S, Bansal-Travers M. Impact of female-oriented cigarette packaging in the United States. Nicotine Tob Res. 2011; 13(7):579-88.
8. Cummings KM, Morley CP, Horan JK, Steger C, Leavell N-R. Marketing to America's youth: evidence from corporate documents. Tob Control. 2002; 11(suppl 1):i5-i17. doi:10.1136/tc.11.suppl_1.i5

9. Zacher M, Bayly M, Brennan E, et al. Personal tobacco pack display before and after the introduction of plain packaging with larger pictorial health warnings in Australia: an observational study of outdoor cafe strips. Addiction. 2014; 109(4):653-62. doi:10.1111/add.12466

10. Dunlop SM, Dobbins T, Young JM, Perez D, Currow DC. Impact of Australia's introduction of tobacco plain packs on adult smokers' pack-related perceptions and responses: results from a continuous tracking survey. BMJ Open. 2014; 4(12):e005836. doi:10.1136/bmjopen-2014-005836

11. Wakefield MA, Hayes L, Durkin S, Borland R. Introduction effects of the Australian plain packaging policy on adult smokers: a cross-sectional study. BMJ Open. 2013; 3(7). doi:10.1136/bmjopen-2013-003175

12. Wakefield MA, Germain D, Durkin SJ. How does increasingly plainer cigarette packaging influence adult smokers' perceptions about brand image? An experimental study. Tob Control. 2008; 17(6):416-21. doi:10.1136/ tc.2008.026732

13. Hammond D, Daniel S, White CM. The effect of cigarette branding and plain packaging on female youth in the United Kingdom. J Adolesc Health. 2013; 52(2):151-7. doi:10.1016/j.jadohealth.2012.06.003

14. White CM, Hammond D, Thrasher JF, Fong GT. The potential impact of plain packaging of cigarette products among Brazilian young women: an experimental study. BMC Public Health. 2012; 12:737. doi:10.1186/1471-2458$12-737$

15. Bansal-Travers M, Hammond D, Smith P, Cummings KM. The impact of cigarette pack design, descriptors, and warning labels on risk perception in the US. Am J Prev Med. 2011; 40(6):674-82.

16. Hammond D, Dockrell M, Arnott D, Lee A, McNeill A. Cigarette pack design and perceptions of risk among UK adults and youth. Eur J Public Health. 2009; 19 (6): 631-7.

17. Hoek J, Wong C, Gendall P, Louviere J, Cong K. Effects of dissuasive packaging on young adult smokers. Tob Control. 2011; 20(3):183-8. doi:10.1136/tc.2010.037861

18. Thrasher JF, Rousu MC, Hammond D, Navarro A, Corrigan JR. Estimating the impact of pictorial health warnings and "plain" cigarette packaging: evidence from experimental auctions among adult smokers in the United States. Health Policy. 2011; 102(1):41-8. doi:10.1016/j.healthpol.2011.06.003 19. Ministry of Health and Population. Brief Profile on Tobacco Control in Nepal. Kathmandu, Nepal, 2009.

20. Ministry of Health and Population, Government of Nepal. Tobacco Product (Control and Regulatory) Act, 2011. Kathmandu. 2012.

21. Canadian Cancer Society. Cigarette Package Health Warnings: International Status Report, Fourth Edition2014.

22. National Health Education Information Communication Centre, Ministry of Health and Population, Government of Nepal. Public Opinion Poll and Compliance Survey on Tobacco Control Legislation in Nepal. Kathmandu, Nepal. 2012.

23. Central Bureau of Statistics. Area and population. Kathmandu (Nepal): Central Bereau of Statistics, Government of Nepal 2011.

24. Van Hal G, Van Roosbroeck S, Vriesacker B, Arts M, Hoeck S, Fraeyman J. Flemish adolescents' perceptions of cigarette plain packaging: a qualitative study with focus group discussions. BMJ Open. 2012; 2(6). doi:10.1136/ bmjopen-2012-001424

25. Moodie C, Mackintosh AM, Hastings G, Ford A. Young adult smokers' perceptions of plain packaging: a pilot naturalistic study. Tob Control. 2011; 20(5):367-73. doi:10.1136/tc.2011.042911

26. Dahal DR. Social composition of the population: caste/ethnicity and religion in Nepal. Population monograph of Nepal. 2003; 1:87-135.

27. Ministry of Health and Population. Annual Report. Nepal. 2012/13. 
28. White V, Williams T, Faulkner A, Wakefield M. Do larger graphic health warnings on standardised cigarette packs increase adolescents' cognitive processing of consumer health information and beliefs about smoking-related harms? Tob Control. 2015; 24(Suppl 2):ii50-ii7.

29. Wakefield M, Coomber K, Zacher M, Durkin S, Brennan E, Scollo M. Australian adult smokers' responses to plain packaging with larger graphic health warnings 1 year after implementation: results from a national crosssectional tracking survey. Tob Control. 2015; 24(Suppl 2):ii17-ii25.

30. Fishbein M. A theory of reasoned action: Some applications and implications. Nebr Symp Motiv. 1980;27: 65-116.

31. Cunningham R, Kyle K. The case for plain packaging. Tob Control. 1995; 4(1):80.

32. Rosenstock IM. The health belief model: Explaining health behavior through expectancies. San Francisco. 1990.

33. Ford P, Clifford A, Gussy K, Gartner C. A systematic review of peer-support programs for smoking cessation in disadvantaged groups. Int J Environ Res Public Health. 2013; 10(11):5507-22. doi:10.3390/ijerph10115507

34. Cahill K, Stevens S, Perera R, Lancaster T. Pharmacological interventions for smoking cessation: an overview and network meta-analysis. Cochrane Database Syst Rev. 2013; 5:CD009329. doi:10.1002/14651858.CD009329.pub2

35. Ranney L, Melvin C, Lux L, McClain E, Lohr KN. Systematic review: smoking cessation intervention strategies for adults and adults in special populations. Ann Intern Med. 2006; 145(11):845-56.

36. Lemmens V, Oenema A, Knut IK, Brug J. Effectiveness of smoking cessation interventions among adults: a systematic review of reviews. Eur J Cancer Prev. 2008; 17(6):535-44. doi:10.1097/CEJ.0b013e3282f75e48 